\title{
Perfil de sensibilidade bacteriana em um hospital público de Teresina
}

\author{
Bacterial sensitivity profile in a public hospital in Teresina \\ Perfil de sensibilidad bacteriana en un hospital publico de Teresina
}

Recebido: 15/11/2021 | Revisado: 17/12/2021 | Aceito: 18/12/2021 | Publicado: 24/12/2021

\author{
Tarcila Ibiapina Andrade \\ ORCID: https://orcid.org/0000-0003-1014-4799 \\ Centro Universitário Uninovafapi, Brasil \\ E-mail: tarcilaibandrade@ hotmail.com \\ Yuthanna Figueiredo Martins Lemos \\ ORCID: https://orcid.org/0000-0002-9855-6175 \\ Centro Universitário Uninovafapi, Brasil \\ E-mail: yuthannamartins96@hotmail.com \\ Williams Cardec da Silva \\ ORCID: https://orcid.org/0000-0002-7167-4876 \\ Centro Universitário Uninovafapi, Brasil \\ E-mail: willcardec@hotmail.com
}

\begin{abstract}
Resumo
Objetivou-se com esse estudo, analisar o perfil de sensibilidade bacteriana por meio de laudos de culturas coletadas em pacientes de Unidade de Terapia Intensiva (UTI), evidenciando o direcionamento para conduta terapêutica. Tratase de um estudo descritivo, retrospectivo, com abordagem quantitativa das culturas de urina, sangue e secreção traqueal. A amostra foi constituída por 330 laudos de culturas positivas de pacientes internados no período de 01 de fevereiro de 2019 a 01 de fevereiro de 2020 na UTI do Hospital de Urgência de Teresina Dr. Zenon Rocha. Do total de laudos analisados, 227 (68,50\%) foram positivos em secreção traqueal, 71 (21,50\%) em hemocultura e 32 (9,70\%) em urocultura. Sendo a Pseudomonas aeruginosa a mais prevalente na secreção traqueal, a Acinetobacter coagulase negativa na hemocultura e Klebsiella pneumoniae na urocultura. Diante disso, é possível afirmar que os resultados obtidos seguiram o padrão de estudos semelhantes realizados em outros locais, com particularidades decorrentes da epidemiologia da região estudada.
\end{abstract}

Palavras-chave: Infecção hospitalar; Unidade de Terapia Intensiva; Antibioticoterapia.

\begin{abstract}
The objective of this study was to analyze the profile of bacterial sensitivity through reports of cultures collected from patients in the Intensive Care Unit (ICU), showing the direction for therapeutic conduct. This is a descriptive, retrospective study with a quantitative approach to cultures of urine, blood and tracheal secretions. The sample consisted of 330 reports of positive cultures from patients hospitalized from February 1, 2019 to February 1, 2020 in the ICU of the Emergency Hospital of Teresina Dr. Zenon Rocha. Of the total number of reports analyzed, 227 $(68.50 \%)$ were positive for tracheal secretion, $71(21.50 \%)$ for blood culture and $32(9.70 \%)$ for urine culture. Pseudomonas aeruginosa being the most prevalent in tracheal secretion, Acinetobacter coagulase negative in blood cultures and Klebsiella pneumoniae in urine cultures. Therefore, the results obtained followed the pattern of similar studies carried out in other locations, with particularities arising from the epidemiology of the region studied.
\end{abstract}

Keywords: Cross infection, Intensive Care Unit; Antibiotic therapy.

\section{Resumen}

El objetivo de este estudio fue analizar el perfil de sensibilidad bacteriana a través de informes de cultivos recolectados de pacientes en la Unidad de Cuidados Intensivos (UCI), mostrando el rumbo de la conducta terapéutica. Se trata de un estudio descriptivo, retrospectivo con abordaje cuantitativo de cultivos de orina, sangre y secreciones traqueales. La muestra estuvo conformada por 330 reportes de cultivos positivos de pacientes hospitalizados desde el 1 de febrero de 2019 al 1 de febrero de 2020 en la UCI del Hospital de Emergencias de Teresina Dr. Zenon Rocha. Del total de informes analizados, $227(68,50 \%)$ fueron positivos para secreción traqueal, 71 (21,50\%) para hemocultivo y $32(9,70 \%)$ para urocultivo. Pseudomonas aeruginosa es la más prevalente en la secreción traqueal, Acinetobacter coagulasa negativo en hemocultivos y Klebsiella pneumoniae en urocultivos. Por tanto, los resultados obtenidos siguieron el patrón de estudios similares realizados en otras localidades, con particularidades derivadas de la epidemiología de la región estudiada.

Palabras clave: Infección hospitalaria; Unidad de Cuidados Intensivos; Antibioterapia. 


\section{Introdução}

Segundo Guevara, Tedesco-Maiullari (2019), Infecções Relacionadas à Assistência à Saúde (IRAS) são definidas como doenças localizadas ou sistêmicas que resultam de uma reação adversa à presença de um agente infeccioso ou de suas toxinas, sem evidência de que a infecção estava presente ou em período de incubação no momento de atenção.

Ademais, Siqueira et al (2018) define IRAS como uma infecção que ocorre até setenta e duas horas antes da admissão quando relacionada a procedimentos diagnósticos e terapêuticos realizados em ambiente hospitalar nesse período.

Ribeiro et al (2019) acrescenta que esse tipo de infecção também abrange aquelas relacionadas a procedimentos realizados ambulatoriamente, durante cuidados domiciliares, e as infecções ocupacionais adquiridas pelos profissionais de saúde.

Alguns fatores são predisponentes no estabelecimento das IRAS, como o tempo de internação prolongado, a necessidade de procedimentos invasivos e o uso indiscriminado de antimicrobianos, que podem causar o desequilíbrio do sistema imunológico e favorecer o aparecimento destas infecções. As IRAS são bastante frequentes e cada vez mais presentes nos hospitais, sendo os usuários de Unidade de Terapia Intensiva (UTI) os mais suscetíveis, por apresentarem mecanismo de defesa mais debilitado e exposição a maior número de procedimentos invasivos (Gil et al, 2018). Dessa forma, as UTIs são consideradas áreas críticas, por existir um risco maior de desenvolvimento de infecções (Teixeira et al., 2019).

Estas infecções têm grande impacto sobre mortalidade hospitalar, duração da internação e custos, em especial quando envolvem resistência aos antimicrobianos (Soares et al, 2019). Como atesta Santos et al (2019) as infecções causadas por patógenos potencialmente resistentes são um problema crescente nas UTIs, sendo o principal motivo para infecções hospitalares, seja pela complexidade dos pacientes críticos ou pelo alto consumo de antimicrobianos nestas unidades.

Muitas vezes se desconhece o mecanismo de transmissão desses microrganismos e sua fonte de disseminação nesta área, questionando-se o papel do ambiente hospitalar, dos instrumentos médicos e dos aparelhos de ventilação como abrigo para este tipo de bactéria, muitas vezes escapando ao papel fundamental que os portadores assintomáticos obedecem à epidemiologia desse tipo de infecção. (Gamboa et al, 2016)

Diversos instrumentos utilizados na prática médica podem ser contaminados por patógenos, de modo que adquirem grande relevância por serem amplamente utilizados e atuarem como fômites na expansão de todos os tipos de patógenos. (Oliva-Menacho et al, 2016).

Esses agentes são transmitidos por contaminação cruzada quando entram em contato com o ambiente de saúde, uma vez que as superfícies servem de abrigo para micro-organismos quando ocorrem falhas na limpeza do ambiente, no processamento de artigos e roupas e no uso de precauções padrão. Com isso, a infecção pode se instalar no corpo do paciente, dependendo das condições de saúde (Paula et al., 2017).

As IRAS, por sua longevidade, podem ser considerados uma das lesões mais antigas e que geram preocupação para a humanidade, visto que ameaçam a qualidade e a evolução dos serviços de saúde, principalmente nos hospitais. A Organização Mundial da Saúde (OMS) reconhece que as IRAS são um problema de Saúde Pública e que são necessárias ações estratégicas para reduzir ou eliminar esse problema, ações que devem ser desenvolvidas em todas as esferas governamentais e de forma articulado. (Hespanhol et al, 2019)

Como a resistência bacteriana e infecções hospitalares são grandes desafios atualmente, é indispensável conhecer o perfil microbiológico do hospital e a epidemiologia local, de forma a estabelecer políticas eficazes para o uso racional de antimicrobianos (Santos et al, 2019).

Diante do exposto, o presente estudo teve como objetivo analisar as culturas de secreção traqueal, hemocultura e urocultura coletadas em pacientes internados em UTI de um hospital de referência do Piauí e descrever o perfil bacteriano. 
Ter informações sobre a incidência de bactérias multirresistentes permite uma melhor estimativa da magnitude do problema epidemiológico de resistência, além de estabelecer comparações entre diferentes serviços clínicos e entre diferentes hospitais, e também avaliar comparativamente sua evolução ao longo do tempo. (Acuña et al, 2017).

A vigilância epidemiológica também permite avaliar a ocorrência de surtos, ou seja, aumento do aparecimento de casos pelo mesmo microrganismo em um mesmo setor. A correta detecção de surtos possibilita investigar suas causas para que assim seja evitado o aparecimento de novos casos. (Santos et al, 2019).

Com atesta Torres et al (2018), a maioria dos pacientes que sofrem bacteremia durante a internação hospitalar tem uma predisposição especial para adquirir infecções intra-hospitalares, seja por fatores associados ao próprio paciente (idade avançada, imunossuprimidos, etc.) ou por serem pacientes críticos, com afecções multissistêmicas, internados em unidades de terapia intensiva (UTI).

Dessa forma, o resultado dessa pesquisa será de grande utilidade para profissionais da saúde, identificando os principais germes patogênicos em ambiente de UTI bem como servindo de referência terapêutica.

\section{Metodologia}

Trata-se de um estudo descritivo, retrospectivo, com abordagem quantitativa das culturas de urina, sangue e secreção traqueal em pacientes internados na Unidade de Terapia Intensiva (UTI), utilizando a técnica de documentos, como sugere Pereira et al, 2018.

A pesquisa foi realizada na UTI do Hospital de Urgência de Teresina Dr. Zenon Rocha - HUT, localizado em Teresina, Piauí. Tal hospital é referência na capital e em outras cidades do estado por ofertar serviços de urgência e emergência, de média e alta complexidade, contando com 26 leitos de UTI. Tendo sida desenvolvida de 01 de junho a 30 de agosto de 2021, com laudos das culturas dos pacientes internados na UTI do HUT.

A amostra é constituída por 330 laudos de culturas positivas de pacientes internados na UTI do Hospital de Urgência de Teresina Dr. Zenon Rocha, selecionados, aleatoriamente, entre os 2160 atendidos na UTI com resultado de cultura positiva. Esse número foi calculado através da fórmula $\mathrm{n}=(\mathrm{z} 2 \cdot 0,25 \cdot \mathrm{N}) /(\mathrm{E} 2(\mathrm{~N}-1)+\mathrm{z} 2 \cdot 0,25)=(1,962 \cdot 0,25 \cdot 222) /(0,052 \cdot 221+1,962 \cdot 0,25)$, na qual, z é o valor crítico, E a margem de erro e $\mathrm{N}$ o tamanho da população, considerando o grau de confiança de $95 \%$ $(\mathrm{z}=1,96)$, margem de erro $\mathrm{E}=5 \%$ e $\mathrm{N}=2160$.

Foram selecionados pacientes internados em ala da UTI do hospital de Urgência Dr. Zenon Rocha, no período de $1^{\circ}$ fevereiro de 2020 a $1^{\circ}$ fevereiro de 2021 e com resultado de cultura positiva e excluídos aqueles que apresentaram infecção comunitária.

Os dados da pesquisa serão coletados a partir do acesso direto aos resultados das culturas dos pacientes internados na UTI, os mesmos se encontram em sistema informatizado, disponibilizado pelo setor de laboratório do referido Hospital. Primeiramente serão selecionados os pacientes dessa ala com diagnóstico de infecção, em seguida será feita a análise da cultura colhida da traqueia, do sangue e da urina e então o resultado será organizado em uma tabela com o auxílio do programa Microsoft Office Excel.

Os dados coletados serão exportados e examinados no programa SPSS (Statistical Package for Social Science) versão 20.0. Estatísticas descritivas do tipo porcentagens e frequências serão calculados e os resultados apresentados por meio de tabelas e gráficos.

A pesquisa é não intervencionista, logo os resultados obtidos nela não irão interferir no tratamento proposto aos pacientes participantes. Os direitos autorais serão resguardados seguindo a lei dos direitos autorais $n^{\circ}$ 9610/98. Projeto aprovado pelo comitê de ética do Centro Universitário Uninovafapi e aprovado na Plataforma Brasil sob o número CAAE 44862421.1.0000.5210, em 27 de maio de 2020. 


\section{Resultados}

Foram analisados 330 resultados de culturas positivas (Figura 1) de três sítios topográficos, sendo 227 (68,50\%) em secreção traqueal, $71(21,50 \%)$ em hemocultura e 32 (9,70\%) em urocultura.

Figura 1: Quantidade de culturas positivas por sítio.

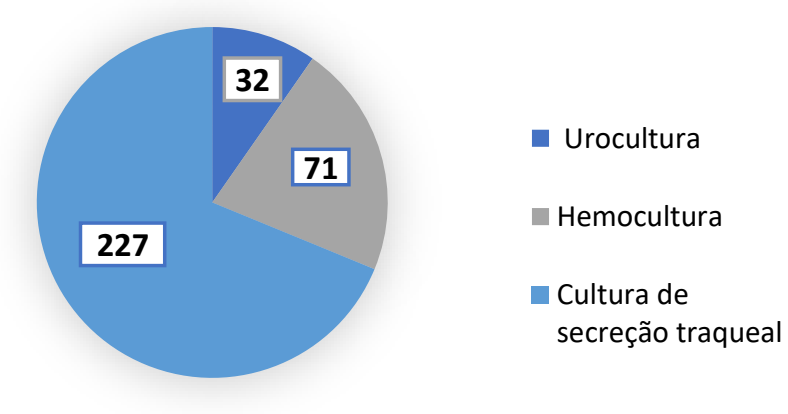

Fonte: Dados de pesquisa (2021)

Nas culturas coletadas em secreções traqueais, as bactérias mais frequentemente encontradas estão expostas na Figura 2. Além delas, foram identificadas Burkholderia cepacia (2,2\%), Enterobacter cloacae (1,7\%), Acinetobacter baumannii/calcoaceticus complexo e Serratia marcescens (ambas com 1,3\%), Proteus vulgaris (0,9\%), seguidas de Providencia stuartii, Enterococcus spp, Streptococcus pyogenes, Proteus mirabilis e Staphylococcus coagulase negativa, que apareceram cada um em apenas 1 cultura, correspondendo a $0,4 \%$.

Figura 2: Bactérias mais frequentes nas culturas de secreção traqueal.

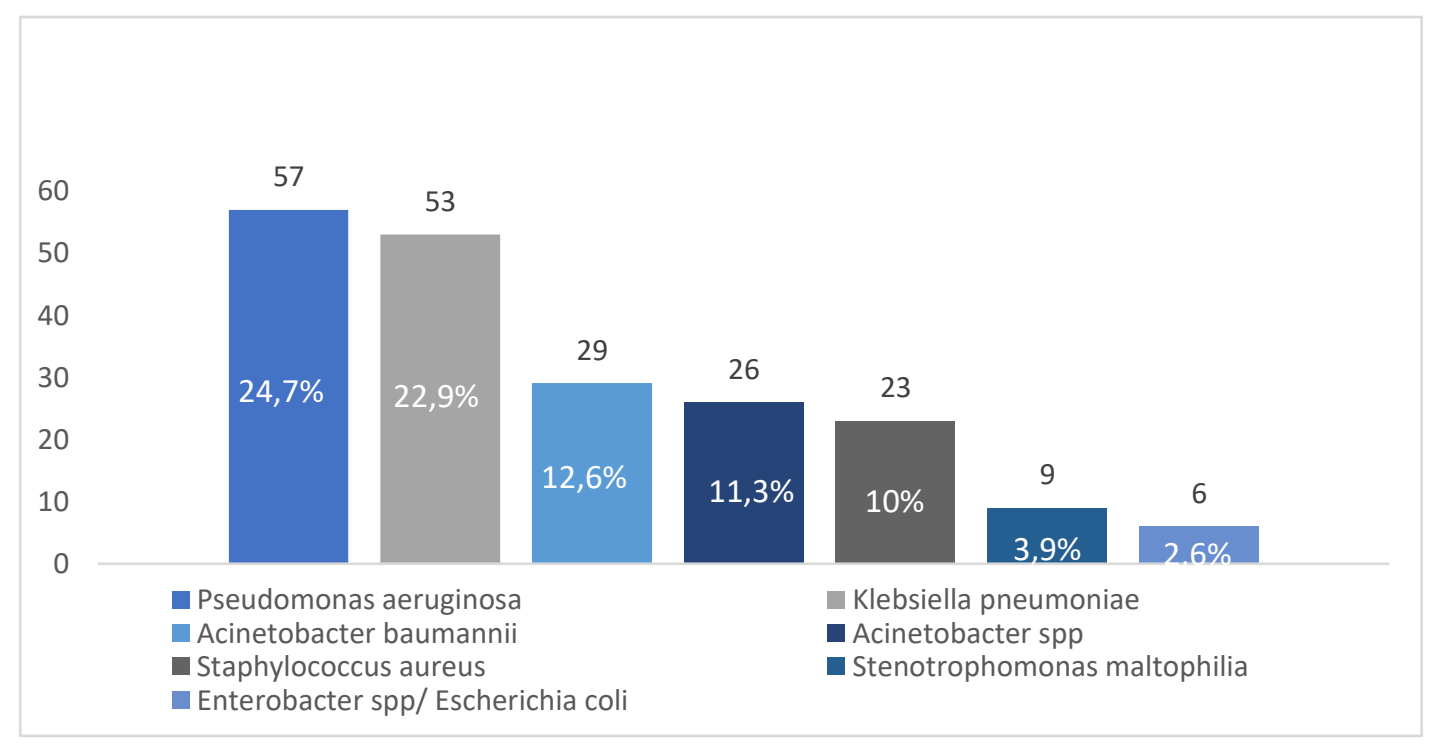

Fonte: Dados de pesquisa (2021).

Nas hemoculturas, por outro lado, a Staphylococcus coagulase negativa é a bactéria mais encontrada, como mostra a Figura 3, seguida de Klebsiella pneumoniae, Staphylococcus aureus, Pseudomonas aeruginosa, Acinetobacter spp, Acinetobacter baumannii, Enterobacter spp, Burkholderia cepacia, Staphylococcus epidermidis e Enterococcus spp. Em 
Research, Society and Development, v. 10, n. 17, e181101724759, 2021

(CC BY 4.0) | ISSN 2525-3409 | DOI: http://dx.doi.org/10.33448/rsd-v10i17.24759

menor número (1,5\% das culturas) aparecem Staphylococcus capitis, Proteus vulgaris, Enterococcus faecalis, Klebsiella oxytoca, Streptococcus pneumoniae, Acinetobacter baumannii/calcoaceticus complexo e Staphylococcus haemolyticus.

Figura 3: Bactérias mais frequentes nas hemoculturas.

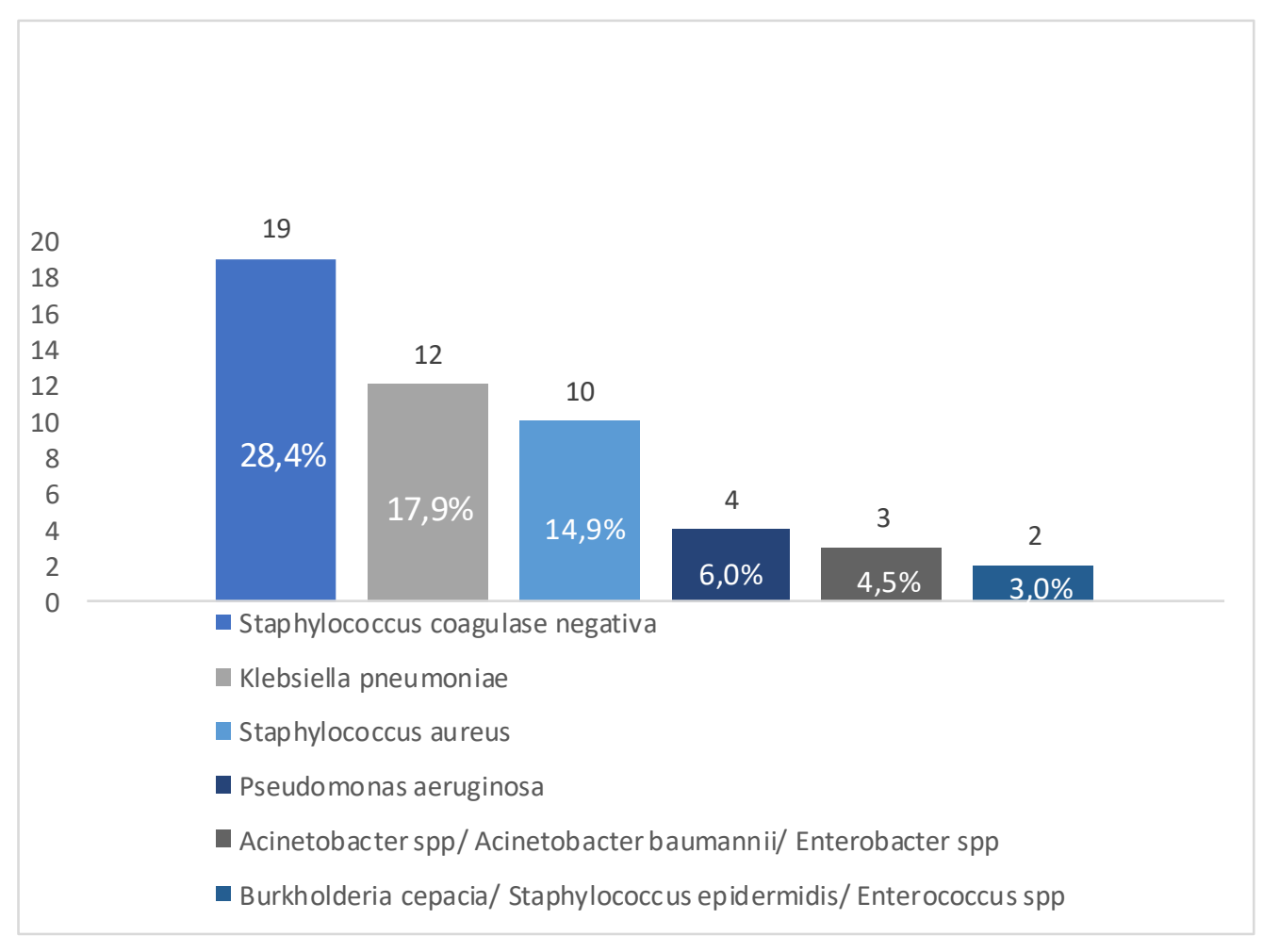

Fonte: Dados de pesquisa (2021).

Figura 4: Bactérias mais frequentes nas uroculturas

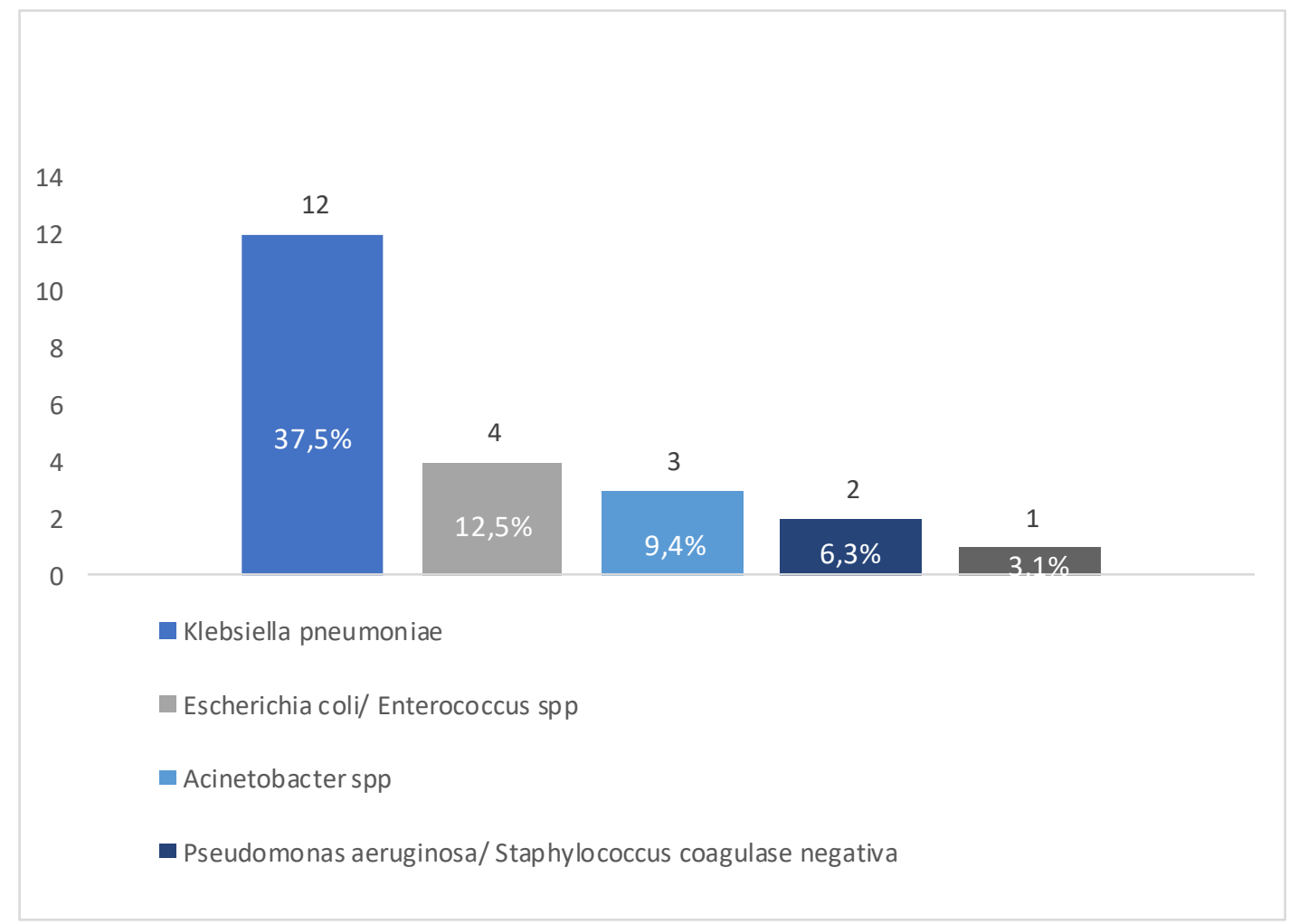

Fonte: Dados de pesquisa (2021) 
A Figura 4 evidencia os resultados obtidos a partir das uroculturas quanto à prevalência das bactérias encontradas neste sítio.

Em todas as 330 culturas analisadas, foram solicitados e executados os antibiogramas, em que foram observados 38 antimicrobianos diferentes. O Quadro 1, mostra a relação entre a sensibilidade da cepa bacteriana para o respectivo antimicrobiano. Nela, não foram expostos os antibióticos não testados para a bactéria correspondente e/ou os que não foram testados em todos os antibiogramas positivos para a mesma. Portanto, não constam no Quadro 1 Aztreonam, Minociclina, Polimixina B, Tigeciclina, Rifampicina, Teicoplanina, Amoxicilina/clavulanato, Ampicilina-sulbactam, Norfloxacina, Nitrofurantoína, Daptomicina, Cefoxitina, Ceftaroline, Fosfomicina, Cefazolina, Ceftriaxona, Cefotaxima e Colistina.

Quadro 1: Relação entre a sensibilidade da cepa bacteriana para o respectivo antibiótico.

\begin{tabular}{|c|c|c|c|c|c|c|c|c|c|c|c|c|c|c|}
\hline \multicolumn{15}{|c|}{ Bactérias/número de isolados } \\
\hline & \multicolumn{2}{|c|}{$\begin{array}{l}\text { Pseudomonas } \\
\text { aeruginosa }\end{array}$} & \multicolumn{2}{|c|}{$\begin{array}{l}\text { Klebsiella } \\
\text { pneumoniae }\end{array}$} & \multicolumn{2}{|c|}{$\begin{array}{l}\text { Acinetobacter } \\
\text { baumanii }\end{array}$} & \multicolumn{2}{|c|}{$\begin{array}{l}\text { Escherichia } \\
\text { coli }\end{array}$} & \multicolumn{2}{|c|}{$\begin{array}{l}\text { Enterococcus } \\
\text { spp }\end{array}$} & \multicolumn{2}{|c|}{$\begin{array}{l}\text { Staphylococcus } \\
\text { coagulase } \\
\text { negativa }\end{array}$} & \multicolumn{2}{|c|}{$\begin{array}{l}\text { Staphylococcus } \\
\text { aureus }\end{array}$} \\
\hline & $N^{*}$ & $\%$ & $\mathbf{N}^{*}$ & $\%$ & $\mathrm{~N}^{*}$ & $\%$ & $N$ & $\%$ & $\mathrm{~N}^{*}$ & $\%$ & $\mathrm{~N}^{*}$ & $\%$ & $\mathrm{~N}^{*}$ & $\%$ \\
\hline Gentamicina & 35 & 55,5 & 54 & 70,1 & 9 & 28,1 & 9 & 90,0 & 5 & 71,4 & 10 & 45,4 & 29 & 87,8 \\
\hline $\begin{array}{l}\text { Piperacilina- } \\
\text { tazobactam }\end{array}$ & 26 & 41,2 & 35 & 45,4 & 4 & 12,5 & 6 & 60,0 & $*$ & & $*$ & & $\cdots$ & \\
\hline Amicacina & $\cdot$ & & 73 & 94,8 & 23 & 71.8 & 10 & 100,0 & $\cdots$ & & $\cdots$ & & $\cdots$ & \\
\hline Ciprofloxacino & 33 & 52,3 & 35 & 45,4 & 4 & 12,5 & 4 & 40,0 & 2 & 28,5 & $\cdots$ & & $\cdot$ & \\
\hline Levofloxacino & $\cdot$ & & $\cdots$ & & 4 & 12,5 & $*$ & & $\bullet$ & & $\cdots$ & & $*$ & \\
\hline Imipeném & 23 & 36,5 & 52 & 67,5 & 4 & 12,5 & 10 & 100,0 & $\cdots$ & & $*$ & & $\cdots$ & \\
\hline Meropeném & $\bullet$ & & • & & 5 & 15,6 & 10 & 100,0 & $*$ & & $\cdots$ & & $\cdots$ & \\
\hline Ertapeném & $\cdots$ & & 49 & 63,6 & $\cdots$ & & $\cdot$ & & $\cdots$ & & $\cdots$ & & $\cdots$ & \\
\hline $\begin{array}{l}\text { Trimetoprima- } \\
\text { sulfametoxazoi }\end{array}$ & $\cdots$ & & 36 & 46,7 & 9 & 28,1 & 2 & 20,0 & $\cdots$ & & 7 & 31,8 & 31 & 93,9 \\
\hline Ampicilina & $*$ & & 0 & 0 & $\cdots$ & & $\cdot$ & & 1 & 14,2 & $\cdots$ & & $\cdots$ & \\
\hline Penicilina & $\cdots$ & & $\cdots$ & & $\cdots$ & & $\cdots$ & & 1 & 14,2 & 1 & 4,5 & $\bullet$ & \\
\hline Vancomicina & $\cdots$ & & $\cdots$ & & $\cdots$ & & $\cdots$ & & $\bullet$ & & 20 & 90,9 & 33 & 100 \\
\hline Linezolida & $\cdots$ & & $\cdots$ & & $\cdots$ & & $\cdots$ & & 7 & 100 & 21 & 95,4 & 32 & 96,9 \\
\hline Ceftazidima & $\cdot$ & & 27 & 35,0 & 3 & 9,3 & $\cdot$ & & $\cdots$ & & $\cdots$ & & $\cdots$ & \\
\hline Oxacilina & $\cdots$ & & $\cdots$ & & $\cdots$ & & $\cdots$ & & $\cdots$ & & 6 & 27,2 & 30 & 90,9 \\
\hline Rifampicina & $\cdots$ & & $\cdots$ & & $\cdots$ & & $\cdots$ & & $\cdots$ & & $\cdot$ & & $\cdot$ & \\
\hline Clindamicina & $\cdots$ & & $\cdots$ & & $*$ & & $*$ & & $\cdots$ & & 6 & 27,2 & 18 & 54,5 \\
\hline Tetraciclina & $\cdots$ & & $\cdots$ & & $\cdots$ & & $\cdots$ & & $\cdot$ & & 18 & & $\cdot$ & \\
\hline Cefepime & 28 & 44,4 & 29 & 37,6 & 4 & 12,5 & 6 & 60,0 & $\cdots$ & & $\cdots$ & & $\cdots$ & \\
\hline Estreptomicina & $\cdots$ & & 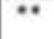 & & $\cdots$ & & $*$ & & 4 & 57,1 & $\cdots$ & & $\cdot$ & \\
\hline Eritromicina & $\cdots$ & & $\cdots$ & & $\cdots$ & & $\cdots$ & & $\cdots$ & & 6 & 27,2 & 15 & 45,4 \\
\hline
\end{tabular}

Fonte: Dados de pesquisa (2021)

Para fins didáticos, foram selecionados os 3 micro-organismos mais frequentes de cada sítio de cultura (urina, sangue e secreção traqueal), sendo a Klebsiella pneumoniae comum a todos, totalizando 7 bactérias. Além das presentes no Quadro 1, foram identificadas também Acinetobacter spp, Stenotrophomonas maltophilia, Enterobacter spp, Burkholderia cepacia, Enterobacter cloacae, Acinetobacter baumannii/calcoaceticus complexo, Serratia marcescens, Proteus vulgaris, Providencia 
stuartii, Streptococcus pyogenes, Proteus mirabilis, Staphylococcus epidermidis, Staphylococcus capitis, Enterococcus faecalis, Klebsiella oxytoca, Streptococcus pneumoniae, Staphylococcus haemolyticus e Morganella morganii.

Não foi especificada a Concentração Inibitória Mínima (MIC) de cada antimicrobiano em todos os antibiogramas analisados. Portanto, não foi possível o detalhamento dessa informação nos dados da pesquisa.

\section{Discussão}

Os antibióticos são uma classe de medicamentos utilizados no tratamento de infecções hospitalares. (Velôso; Campelo, 2017). O uso abusivo e inadequado dos antimicrobianos tem sido reconhecido como a principal causa do crescimento acelerado de resistência microbiana, em algumas regiões da América Latina, cerca de $75 \%$ dos antibióticos são prescritos de forma inadequada e a resistência bacteriana foi observada em até 50\% das cepas isoladas (Santos et al, 2019).

Araujo et al (2018) aponta as infecções do trato respiratório como as mais comuns entre pacientes internados em UTIs, seguidas de infecção do Trato Urinário (ITU) e infecção da corrente sanguínea. Observou-se nos resultados das culturas coletadas que a prevalência de infecções no trato respiratório é, de fato, a maior. Entretanto, em segundo lugar as infecções da corrente sanguínea e, por último, as do trato urinário.

De acordo com Yang et al (2020), a Pseudomonas aeruginosa é a causa mais comum de infecções do trato respiratório. Nas ITUs, segundo Masson (2020), a Escherichia coli predomina, seguida do Staphylococcus saprophyticus. Já nas hemoculturas, o principal patógeno encontrado, segundo Lima et al (2019), foi a bactéria Gram+ Staphylococcus coagulase negativa, o que difere de outros estudos epidemiológicos sobre infecções em pacientes internados em Unidades de Terapia Intensiva (UTIs), nos quais o principal patógeno encontrado foi o Staphylococcus aureus.

Nas UTIs onde foram coletadas as culturas analisadas, confirmou-se que a Staphylococcus coagulase negativa lidera em números de infecção, também opondo-se a outros estudos realizados em UTI, uma vez que a Staphylococcus aureus ocupa o terceiro lugar.

Em concordância com Yang et al (2020), a Pseudomonas aeruginosa se destaca entre as demais nas infecções respiratórias. Entretanto, há divergência com Masson (2020) nos resultados obtidos com relação à bactéria mais frequente na urocultura, pois observou-se Klebsiella pneumoniae em primeiro lugar, seguida da Escherichia coli (E. coli).

A resistência bacteriana constitui um relevante problema de saúde pública que tem se tornado cada vez mais importante, tanto pelo aumento de sua incidência, bem como pelo surgimento de novos mecanismos de resistência que limitam as alternativas terapêuticas. Isso tem um impacto especial nas unidades de terapia intensiva, que concentram a maior incidência de bactérias multirresistentes e as infecções clínicas mais graves, o que determina um maior consumo de antimicrobianos (Acuña et al, 2017).

Como expõe Waele (2017), a antibioticoterapia empírica deve basear-se no conhecimento da epidemiologia local. Dessa forma, revela-se de extrema importância a realização do antibiograma associado à cultura e tranquilizador o fato de $100 \%$ das culturas estarem acompanhadas de antibiogramas nas amostras coletadas.

\section{Conclusão}

É possível concluir que os resultados obtidos seguiram o padrão de estudos semelhantes realizados em outros locais, com particularidades decorrentes da epidemiologia da região estudada. O sítio com maior frequência de culturas positivas foi secreção traqueal, seguida de sangue e, por último, urina.

A bactéria encontrada com maior prevalência nas culturas de secreção traqueal foi a Pseudomonas aeruginosa, enquanto que nas hemoculturas foi a Staphylococcus coagulase negativa e na urocultura foi a Klebsiella pneumoniae.

Portanto, conhecer os patógenos e seus respectivos perfis de sensibilidade, orienta na escolha do tratamento mais 
eficaz e responsável das infecções.

Portanto, é importante a realização periódica de pesquisas científicas como esta que analisem o perfil de sensibilidade bacteriana, de modo a auxiliar a conduta terapêutica e, dessa forma, a diminuir a quantidade de casos de infecção, bem como a indução de resistência antimicrobiana.

\section{Referências}

Acuña, M. P. \& Cifuentes, M. \& Silva, F. \&Rojas, A. \&Cerda, J. \& Labarca, J. (2017). Incidencia de bacterias multi-resistentes en unidades de cuidados intensivos de hospitales chilenos. Revista Chilena de Infectología, 34(6), 570-575.

Araujo, P. L. \& Mendonça, A. E. O. \& Medeiros, R. A. \& Souza de Neto, V. L. \& Nobre, T. T. X. \& Costa, I. K. F. (2018). Prevalência de infecção relacionada à assistência à saúde em pacientes internados em unidade de terapia intensiva. Revista eletrônica trimestral de enfermaria, 17 (4), $278-315$.

Gamboa, F. R. A. \& Martinez, S. L. A. \& Alarcón, D. M. C. \& Cusicanqui, L. A. C. \& Valverde, D. A. F. \& Cecilio, M. M. M. \& Neftali, R. C. \& Vásquez, G. G. \& Sipión, R. S. D. (2016). Portadores de bacterias multirresistentes de importancia clínica en áreas críticas (UCI-UCIN) de un hospital al norte del Perú. Horizonte Médico, 16(3), 50-57.

Guevara, A. \& Tedesco-Maiullari, R. (2019). Conocimiento sobre infecciones asociadas a la atención de la salud en estudiantes de bioanálisis. Acta bioquím. clín. latinoam., 53(1), 53-61.

Gil, A. C. \& Bordignon, A. P. P. \& Catro, E. A. R. \& Castro, S. T. \& Rafael, R. M. R. \& Pereira, J. A. A. (2018). Avaliação microbiológica de superfícies em terapia intensiva: reflexões sobre as estratégias preventivas de infecções nosocomiais. Revista Enfermagem UERJ, 26, e26388.

HespanhoL, L. A. B. \& Semírames, C. S. R. \& Ribeiro Júnio, O.C. \& de Araújo, T. S. \& Martins, A. B. (2019). Infección relacionada con la Asistencia a la Salud en Unidad de Cuidados Intensivos Adulto. Enfermería Global, 18(53), 215-228.

Lima, L. R. \& Cunha, G. S. P. \& Nogueira, K. S. \& Comar, S. R. (2019). Contagem automatizada de granulócitos imaturos em pacientes de uma unidade de terapia intensiva com suspeita de infecção. J Bras Patol Med Lab, 53(3), 148-149.

Masson, L. C. \& Martins, L. V. \& Gomes, C. M. \& Cardoso, A. M. (2020). Diagnóstico laboratorial das infecções urinárias: relação entre a urocultura e o EAS. $R B A C, 52(1), 77-81$.

Oliva-Menacho, J. E. \& Garcia-Hjarles, M. A. \& Oliva-Candela, J.A. \& De La Cruz-Roca, H. S.(2016). Contaminación con bacterias patógenas de estetoscopios del personal médico en un hospital de nivel III en Lima, Perú. Revista Medica Herediana, 27(2), 83-88.

Padilla, Y. G. S. \& Cabrera, L. S. \& Hung, M. E. D. \& Cabrillana, M. J. M. (2019). Presencia de microorganismos en teléfonos móviles del personal de cuidados intensivos de un hospital de españa. Revista Peruana de Medicina Experimental y Salud Pública, 36(4), 676-680.

Paula, A. O. \& Salge, A. K. M \& Palos, M. A. P. (2017). Infecciones relacionadas con la asistencia a la salud en unidades de terapia intensiva neonatal: una revisión integradora. Enferm. glob, 16(45), 508-536.

Pereira, A. S., Shitsuka, D. M., Parreira, F. J. \& Shitsuka, R. (2018) Metodologia da pesquisa científica [e-book]. Santa Maria, RS: UFSM, NTE, 2018. 1 ebook

Ribeiro, T. de S.\& Ribeiro, R. A. A. S. \& Batista, K. S. \& Aquino, S. R. \& Naue, C. R. (2019). Ocorrência e perfil bacteriano de culturas coletadas em pacientes internados na unidade de terapia intensiva em um hospital terciário. HU Revista, Biblioteca Virtual em Saúde, 45(2), $122-133$.

Santos, A. C. J. A. \& Cardoso, D. R. \& Neto, M. P. L. \& Britto, M. H. R. M. (2019). Análise do perfil de antibióticos utilizados em unidade de terapia intensiva (UTI) de um hospital público de Teresina-PI. Brazilian Journal of Surgery and Clinical Research, 29(1), 39-42.

Santos, J. A. \& Urzedo, J. E. \& Osme, S. F. \& Santos, M. R. \& Fontes, A. M. S. \& Roder, D. V. D. B. (2019). Surtos bacterianos em uma Unidade de Terapia Intensiva Neonatal: histórico de cinco anos. Arquivos de Ciências da Saúde, 26(2), 136-140.

Siqueira, C. C. M. \& Guimarães, A. C. \& Mata, T. F. D. \& Pratte-Santos, R. \& Raymundo, N. L. S. \& Dias, C. F. \& Moraes, R, (2018). Prevalência e perfil de susceptibilidade aos antimicrobianos de microrganismos em um hospital universitário de Vitória (ES), Brasil. J. Bras. Patol. Med. Lab, 54(2), 76-82.

Soares, M. A. \& Rodrigues, N. M. \& Menezes, M. R. O. \& Gerace, D. N \& Duarte, C. M. \& Brandão, P. M. \& Borges, L. F. A. (2019). Microrganismos multirresistentes nas mãos de profissionais de saúde em Unidades de Terapia Intensiva. Revista de Epidemiologia e Controle de Infecção, 9(3), 187-192.

Teixeira, K. C. F. \& Santos, L. M. \& Azambuja, F. G. (2019). Análise da eficácia da higiene oral de pacientes internados em unidade de terapia intensiva em um hospital de alta complexidade do sul do Brasil. Rev. Odontol. Univ. Cid, 30(3), 234-45.

Torres, A. H. \& Goméz, A. G. \& Pensado, J. C. P. \& Rives, Y. A. \& Castillo, E. F. (2018). Bacteriemias en la unidad de cuidados intensivos. Revista Cubana de Medicina Militar, 4(1), 10-20.

Velôso, D. S. \& Campelo, V. (2017). Incidência de infecções bacterianas e o perfil antimicrobiano utilizado no tratamento dos pacientes de um hospital de ensino. Revista Interdisciplinar Ciências e Saúde. 4(2), 19-28.

Walle, J. J. (2018). O que todo intensivista deveria saber sobre o tratamento da peritonite na unidade de terapia intensiva. Rev Bras Ter Intensiva, 30(1), 9-14.

Yang, X. \& Lai, Y. \& Li, C. \& Yang, J. \& Jia, M. \& Sheng, J. (2020). Molecular epidemiology of Pseudomonas aeruginosa isolated from lower respiratory tract of ICU patients. Brazilian Journal of Biology, 81 (2), 351-360. 